\title{
Theoretical Foundations of Africa's Economic Transformation and Growth
}

\author{
Joseph Atta-Mensah \\ Capacity Development Division, United Nations Economic Commission for Africa, Addis Ababa, Ethiopia \\ Email: atta-mensahj@un.org
}

How to cite this paper: Atta-Mensah, J. (2017) Theoretical Foundations of Africa's Economic Transformation and Growth. Theoretical Economics Letters, 7, 11501178.

https://doi.org/10.4236/tel.2017.75078

Received: May 27, 2017

Accepted: July 18, 2017

Published: July 21, 2017

Copyright $\odot 2017$ by author and Scientific Research Publishing Inc. This work is licensed under the Creative Commons Attribution International License (CC BY 4.0).

http://creativecommons.org/licenses/by/4.0/

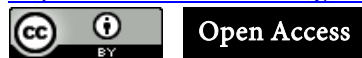

\begin{abstract}
This paper provides the theoretical underpinnings of growth models to explain structural economic transformation in Africa. The paper suggests that endogenous growth model is the key for understanding long-run growth of economies through the accumulation of knowledge. Private and public investments in knowledge and Research and Development (R \& D) have longrun effects on growth. Since small changes in the growth rate of an economy can cumulate into large changes in the standard of living over a generation or more, government policies can have a large impact on economic welfare. Furthermore, endogenous growth models provide a richer structure that can add insight into the mechanics of growth. The implications of the growth models examined in this paper are that for an African country to achieve economic transformation through an interrelated processes of structural change that accompany economic development, and growth has to be at sustainable high levels for a very long time. Furthermore, it is important African policymakers work hard to circumvent diminishing marginal productive of key factors of production. It is also important that adequate resources are invested by African government in research and development, allowing for technological progress, innovations and accumulation of knowledge. A combination of these factors is the necessary ingredient for sustainable high levels of growth. The endogenous growth models hold a lot of promise for the structural economic transformation of African economies. The paper offers policy advice for African countries attempting to transform and build resilient economies.
\end{abstract}

\section{Keywords}

Structural Economic Transformation, Growth Models, Policy Advice

\section{Introduction}

Until the crash of global commodity prices, the buss around every corner of Africa 
is the narrative that Africa is rising. The interpretation and reasons for this "Africa rising" story varies from analyst to analyst. However, what everyone agrees on is that the continent's economic performance at the turn of the millennium has been robust, growing at an annual average rate of 5 percent. It is worth noting that that some of the economies on the continent are among the world's fastest-growing economies. The optimism beaming around the globe for Africa has led some commentators to predict that the average African economy will outpace its Asian counterpart in the foreseeable years. According to the respected Economist magazine, Africa which it dubbed a decade ago as a hopeless continent is currently bullish about the economic prospects of the continent, calling it the hopeful continent.

Although no definitive explanation can be offered, one could suggest that the positive economic performance of Africa is due to the sound policies run by many African countries. These policies, which inoculated the African economies against the severe ramification of the 2007 financial crisis included: low-inflationary monetary stance, prudent fiscal management (strengthened budget positions, reduced debt burdens and reformed tax structure), and reasonable foreign currency reserve cushion. Improved fiscal position allowed countries to use the budget to counteract the crisis, rather than making it worse. Fiscal policy was therefore expectedly countercyclical in many African countries at the time of the crisis. It should be said that the fiscal cushion helped a great deal to protect the poor and vulnerable as social spending was not cut during the crisis.

Despite the current robust economic performance, Africa should not be complacent as it remains vulnerable to shocks from different sources. These shocks could potentially come from volatility in commodity prices, natural disasters, climate change, wars and conflicts as well as weakened flow of remittances, aid, and financial flows. The challenge for Africa is to continue to pursue an agenda of strong inclusive-growth at the same time reinforcing its resilience to shocks. This requires that Africa stay on course on its pursuant of sound macroeconomic policies. Hence policy buffers must remain in place to allow for future countercyclical responses including prudent fiscal policy and the use of reserves. Social safety nets needs to be strengthened as well. Social and income inequalities must also be aggressively addressed so as not to heighten tensions within the population in times of economic downturn and make shocks more destabilizing. This clearly indicates that for Africa to safeguard its gains it is important have a good understanding about economic growth is about. The purpose of this paper is to contribute to the discussions on economic growth within the framework of economic transformation.

\section{Economic Transformation and Africa's Growth Performance}

As noted earlier, African economies are performing very well. In recent years, it has been growing robustly at an average rate of about 5 percent. Analysts ascribe that one of the reasons for the good economic performance of African economies 
has to do with the transformation of the economies. In other words, we are witnessing in Africa a process of economic development which is characterized by a period of rapid per capita growth combined with structural change. This is in line with what [1] defines as economic transformation. He defines economic transformation as the interrelated processes of structural change that accompany economic development. African governments have been implementing smart economic policies which are causing a poor, rural-based African country to be moving towards middle-income status with a rising share of industry and services in gross domestic product (GDP) and employment. As witnessed in Latin American countries and Asia and now in some parts of Africa, the transformation does exhibit some common characteristics. First, during early stages of the transformation, one observes significant changes to economic structures. As explained by [2] and [3], changes to the economic structures occur because industrialization ignites accelerated increases in the share of manufacturing in the economy and a consequent decline of the share of agriculture. A second observation is that the share of the total labour force employed in the agricultural sector will fall during the transformation process while that in other economic sectors rises. Third, agricultural productivity rises as a result of the use of modern agricultural technology and better seedlings. Lastly, as the main driver of the country's economy shifts from rural areas to cities there is bound to be significant increase in the degree of urbanization. What these patterns mean is that economic transformation leads to the rise in the overall productivity and income per capita of the country as well as the rapid creation of new and higher-paid jobs. Furthermore, with the transformation, the country moves away from the production of primary products and into value-added products. Consequently, the economy becomes integrated in the global supply chains and as a result of its trade with the rest of the world there is continuous learning by doing and upgrading of new technologies and skills sets as well as the expansion of manufacturing capacities.

Africa's robust economic performance at the turn of the millennium has been impressive. However, for economic transformation to have greater impact requires that African countries' growth be significant (perhaps in double digits) and sustainable. It has to be noted in the short term, the transformation process could lead to uneven growth and rising income inequality, which is being observed in a number of African countries. [4] was first to suggest that income inequality might follow an inverse $\mathrm{U}$ shaped relationship during the transformation process. The Kuznets curve predicts that initial stages of the industrialization process leads to an increase in income inequality. However, as the process continues there is significant decline in inequality as wages rise with higher labour productivity.

African policymakers must bear in mind that as economic transformation leads to modernization of a country's economy, society and institutions are also affected because human life, values, norms, beliefs and customs are also transformed from a traditional to a modern society. Moreover, shifts in production 
structures during transformation lead to changes in incentive structures, educational requirements, and the relative positions of different groups in society. [4] further argues that urbanization results in shifts in family formation, gender relations and personal status. The transformation also changes transport and communication services as production and distribution centres are opened up and connected to markets. The legal system has a vital role to play as new laws are needed to preserve and uphold institutional innovations and property rights.

The impacts of economic transformation clearly suggest that it is extremely important that there is a clear understanding on the foundations of economic growth and therefore growth theory. An understanding of the fundamentals and characteristics of growth theory will allow policymakers to make sound decisions on the type of transformation it needs to embark on. Interventionist policies will then be targeted towards areas of increased and sustained growth which will deliver the type of economic transformation desired. Hence the next section examines the fundamentals of growth theory and its relation to Africa's growth performance.

\section{Growth Theory and Africa's Economic Performance}

As noted, earlier African countries have been performing at robust growth rates since the beginning of the 21 st century. In this section a focus is placed on how growth theory provides some answers to underpinning recent economic performance of Africa.

African countries cannot achieve credible economic transformation without sustainable economic growth. And there cannot be sustainable economic growth without structural transformation of the economy. Hence economic transformation and economic growth goes hand-in-hand. With the right enabling environment, most industrialized economies do expand over time. Part of the factors responsible for the growth of economies can be traced to rise in the population, and therefore the economy's labour force. However, the labour force cannot tell all the story as evidence show that if one was to control for the effects of a rising labour force, positive average growth still remains.

Discussions in the literature on growth tend to make distinctions between average growth over time and the variance around this average. Again in the literature we find that the economy's long-run average growth rate are typically studied under the heading of "growth theory" while short-run year-to-year fluctuations in growth are studied under the banner of "business cycle theory": The examination or inquiry of both the business cycle and long-term growth has been the preoccupation of macroeconomic scholarly work for a long time.

The study of the business cycle theory can be traced to the Great Depression. The economic and human costs of this deep and protracted downturn of the global economy in 1930s made understanding business cycles and what policymakers could do to mitigate the depression a pressing economic and social issue. "Keynesian" economists at the time led by John Maynard Keynes recommended that governments and policymakers should take an active role in smoothing 
business cycles through expansionary fiscal policies. In the 1950s and 1960s Keynesian economics became the predominant framework in macroeconomics and receptive governments in many countries pursued increasingly activist macro-stabilization policies. Some may even argue that activist policies of governments to stabilize economies during the 2007 financial crisis were those taken from the play book of Keynesian economists.

The period of the great depression was also very important for the study of growth theory. A lot of studies were carried out in the 1950s and 1960s on aggregate economic growth, both theoretical and empirical work. However, the dual "evils" of high inflation and unemployment in the 1970s in most countries shifted the attention of macroeconomists back to business cycles. Since the mid1980s, however, growth theory has again begun to attract increased attention in macroeconomics and more so in recent years in Africa.

The rejuvenation of interest in growth theory following the financial and economic crisis of 2007 can be traced in part to a growing realization that governments' efforts to fine tune short-run economic performance are imperfect at best and can be counterproductive. The overly expansionary policies pursued in many industrialized countries in the late 1960s and 1970s failed to improve economic performance, and resulted instead in a sharp rise in inflation. It must be noted that the quantitative easing $(\mathrm{QE})$ pursued by the Federal Reserve Board can be said to have stemmed the tide for the US economy tails pinning into deeper recession.

Learning from the little successes of short run stabilization policies, economists are studying what enabling environment is conducive for strong and sustained medium- and long-run growth. This of course requires a clear understanding of how growth comes about in competitive market economies. The observed diversity of the growth experiences of different countries suggests that certain features of an economy are more conducive to fostering strong growth than others. Isolating the key ingredients of growth is central to forming well informed policies for long-run prosperity. Responding to this challenge, economists have generated a rapidly expanding literature on the theory of long-run growth and devoted increased attention to the empirical evidence regarding growth.

\section{Can Neoclassical Growth Models Explain the Growth of African Economies?}

This Section examines whether neoclassical growth models offer explanations for the economic performance of African economies. The current study on growth builds on the growth model that was developed in the 1950s and 1960s. [5] was first to summarize long-run growth into a simple neoclassical model. The model provides a very simple and highly aggregated framework for studying growth. Theirs begin with the notion that the overall level of output of a country can be simplified or modelled as being produced by an aggregate production technology that fully uses the national capital stock and the total labour supply as its inputs. The central feature of this aggregate production technology is that 
investment in capital is subject to diminishing returns. What this means is that if the number of workers is held constant, using more capital in production will increase output but at a decreasing rate. The intuitive idea is fundamental to much of economics.

What do economists mean by diminishing returns? To explain, let us consider a farm that has ten labourers working in it with one tractor. Holding the number of labourers at ten, what is the impact of additional tractors. The addition of the first few tractors increases productivity of the labourers substantially as less time will be required to cultivate the land. Additional increase in the number of tractors will further boast productivity of the land. However, the increase in productivity is not as great as for the first few tractors, since with their greater availability the tractors now sit idle more often. Increasing the number of tractors further continues to raise productivity, but at some point every labourer will have a tractor that they can use. Increasing the number of tractors beyond this point will not raise productivity at all. The economy, as a whole, faces much the same situation as the farm. With the total supply of workers limited by the size of the available labour force increasing the capital intensity of production will raise aggregate output, but to an ever decreasing extent.

\subsection{Solow's Growth Model}

Borrowing from Solow's model let assume a representative closed African economy with competitive markets, identical rational economic agents and a production function for the single good $Y_{t}$ of the form:

$$
Y_{t}=K_{t}^{\alpha}\left(A_{t} L_{t}\right)^{1-\alpha}, 0<\alpha<1
$$

where $A_{t}$ is the state technology, $K_{t}$ is the capital stock, and $L_{t}$ is the labour force, assumed equal to the economy's population

The consumer is assumed to maximise a preference function of the form:

$$
\max \int_{0}^{\infty} U\left(C_{t}\right) \mathrm{e}^{\rho t} \mathrm{~d} t, U\left(C_{t}\right)=\frac{C_{t}^{1-\alpha}}{1-\sigma}, \sigma>0
$$

$U(\cdot)$ is a constant-relative-risk-aversion utility function and the coefficient of relative risk aversion is:

$$
-\frac{C \frac{\mathrm{d}^{2} U(C)}{\mathrm{d} C^{2}}}{\frac{\mathrm{d} U(C)}{\mathrm{d} c}}=\sigma
$$

$\sigma$ is the is also the reciprocal of the elasticity of inter-temporal substitution between two periods of time and $\rho$ is the rate of time preference.

Now it is assumed that output $Y_{t}$ is allocated between aggregate consumption $C_{t}$ and capital accumulation $\dot{K}_{t}$. For simplicity let us assume that depreciation of capital is zero. Hence the closed form economy's budget constraint is:

$$
Y_{t}=C_{t}+\dot{K}_{t}
$$

Social planners face the challenge of allocating resources efficiently and there- 
fore would have to maximise Equation (2) subject to the budget constraint, Equation (4). In other words, the social planner allocate resources by maximizing at date $t$ the current value of the Hamiltonian:

$$
H_{t}=\frac{C_{t}^{1-\alpha}}{1-\sigma}+\theta_{t}\left[K_{t}^{\alpha}\left(A_{t} L_{t}\right)^{1-\alpha}-C\right]
$$

The solution to Equation (5) is obtained by imposing the following conditions:

First order condition:

$$
\frac{\mathrm{d} H_{t}}{\mathrm{~d} C_{t}}=0
$$

Co-State condition:

$$
\frac{\mathrm{d} H_{t}}{\mathrm{~d} K_{t}}=\rho \theta_{t}-\dot{\theta}
$$

Transversality Condition:

$$
\lim _{t \rightarrow \infty} \mathrm{e}^{-\rho t} \theta_{t} K_{t}=0
$$

[6] suggests that the first order conditions (Equation (6)) implies that every instant of time the shadow price of investment $\theta_{t}$ must equal the marginal utility of consumption. In other words, at each instant of time, the social planner will allocate output between consumption and investment in an optimal manner such that the marginal gain from a unit increase in consumption is just equal to the marginal loss of a unit decrease in investment.

The co-state (Equation (7)) is the Fischer equation which states that, at every moment of time, the sum of the marginal product of capital and the capital gain per unit of capital must equal the pure rate of time preference.

The transversality condition (Equation (8)) suggests that the value of capital must tend to zero in the long run. It helps to close the model as well as the solution to maximization challenge facing the social planner.

Using Equation (5) and Equation (6) implies:

$$
C^{-\sigma}=\theta
$$

Taking the logarithm of Equation (9) and differentiating implies the growth rate of consumption is $g_{c}$ :

$$
\frac{\dot{C}}{C}=-\frac{1}{\sigma} \frac{\dot{\theta}}{\theta}
$$

Combining Equations (5) and (7) implies:

$$
\theta \alpha K_{t}^{\alpha-1}\left(A_{t} L_{t}\right)^{1-\alpha}=\rho \theta_{t}-\dot{\theta}
$$

or,

$$
\frac{\dot{\theta}}{\theta}=\rho-\alpha K_{t}^{\alpha-1}\left(A_{t} L_{t}\right)^{1-\alpha}
$$

Inserting Equation (12) into Equation (10) gives the growth rate of consumption: 


$$
g_{c}=\frac{1}{\sigma}\left[\alpha K_{t}^{\alpha-1}\left(A_{t} L_{t}\right)^{1-\alpha}-\rho\right]
$$

Since $\rho$ and $\sigma$ are constants, Equation (13) implies that a positive balanced growth path of consumption must equal the marginal product of capital $\alpha K_{t}^{\alpha-1}\left(A_{t} L_{t}\right)^{1-\alpha}$ above the discount rate $\rho$. Given that rate of time preference or discount rate is a very small number the log-differentiation of Equation (13) yields:

$$
\dot{g}_{c}=(\alpha-1) g_{K}+(1-\alpha)\left(g_{A}+g_{L}\right)=0
$$

or

$$
g_{K}=g_{A}+g_{L}
$$

where $g_{K}$ is the growth rate of capital, $g_{A}$ is the growth rate of technology and $g_{L}$ is the growth rate of labour. What Equation (15) implies is that the growth rate of capital is the sum of growth rate of technology and growth rate of labour. This implies that for sustainable growth to be achieved by an African country, the growth rate of capital accumulation must be equal to the sum of the growth rate of technology and labour. To extend the discussion further, let us examine the analysis with and without technological progress.

\subsubsection{Solow's Model without Technological Progress}

If we make the assumption no technological progress and extend further to say no population growth, then: $g_{A}=0$ and $g_{L}=0$. This implies from Equation (15) that $g_{K}=0$. Now from the log-differentiation of the production function (Equation (1)) the growth rate of output will be:

$$
g_{Y}=\alpha g_{K}+(1-\alpha)\left(g_{A}+g_{L}\right)
$$

Given that $g_{K}=g_{L}=g_{A}=0$ then it implies that from Equation (16) $g_{Y}=0$.

The implication of the above conditions is that technological growth is central for an economy to growth. Hence Africa's transformation cannot take off if there is no technological progress.

Now for $g_{K}=0$ implies $\dot{K}=0$. Hence we rearrange Equation (4) as:

$$
C_{t}=Y_{t}=K_{t}^{\alpha}\left(A_{t} L_{t}\right)^{1-\alpha}
$$

Hence from log-differentiation, the growth path of consumption is:

$$
g_{c}=\alpha g_{K}+(1-\alpha)\left(g_{A}+g_{L}\right)=0
$$

The above analysis indicates that in an economy with constant population, per-capita underlying variables (output, consumption, capital) grow at the same rate. This implies for balanced growth path solution of Solow's model for constant $\mathrm{A}$ and constant $\mathrm{L}$ requires:

$$
g_{c}=g_{Y}=g_{K}=0
$$

It is important to note that the economy has zero growth in the long-run because of diminishing returns to capital. This means:

$$
\frac{\mathrm{d}^{2} y}{\mathrm{~d} K^{2}}=\alpha(1-\alpha) K_{t}^{\alpha-2}\left(A_{t} L_{t}\right)^{1-\alpha}<0
$$


Equation (20) is negative because $0<\alpha<1$. As explained by Solow, the implication of diminishing of the productivity of capital implies that the transitional dynamics allows the accumulation of capital to eventually drive its marginal productivity down until it equates $\rho$. At this point capital accumulates to its steady state $K^{*}$ for which the economy stops growing. Also although growth of the economy will occur there may not be structural changes to accompany the growth. Hence there may not be transformation of the economy as there is no technological progress.

\subsubsection{Solow's Model with Technological Progress}

In this model technology is allowed to grow at a positive rate $g_{A}>0$. Population continues to be held constant and therefore $g_{L}=0$. Hence from Equation (15) $g_{K}=g_{A}$ and therefore, from Equation (16): $g_{Y}=\alpha g_{K}+(1-\alpha)\left(g_{A}+g_{L}\right)=g_{A}$. Also from Equation (18): $g_{C}=g_{K}=g_{A}$.

This means that for an economy with constant population the growth rates of the underlying variables are the same:

$$
g_{C}=g_{K}=g_{A}=g_{y}=\bar{g}
$$

From Equation (4) the savings of the economy is:

$$
S_{t}=Y_{t}-C_{t}=\dot{K}_{t}
$$

Given that savings in each period must equal investment, $I_{t}$. Hence in each period we can express investment per output as:

$$
\frac{I}{Y}=\frac{\dot{K}}{Y}=\frac{K g_{K}}{Y}=\frac{g_{K}}{Y / K}
$$

Using Equations (13) and (21) Equation (23) becomes:

$$
\frac{I}{Y}=\frac{\alpha \bar{g}}{\sigma \bar{g}+\rho}
$$

or,

$$
I=\beta Y, \beta=\frac{\alpha \bar{g}}{\sigma \bar{g}+\rho}
$$

The interpretation of Equation (25) is that when an economy reaches the balance growth path, it will be saving and investing a constant fraction of its income. Also $\beta$ can be considered as the marginal rate of savings. Equation (25) suggests that it is imperative for Africa countries to increase their savings rate which in tend will raise the level investments, the ingredient need to support economic transformation.

A key question is what is happening to capital in the longrun. With the growth rate of technology, $g_{A}$, being positive implies that output per-capita would grow at a positive constant $\bar{g}$ in the longrun (Equation (21)). This means that with technological progress, capital can grow in the longrun without decreasing its marginal productivity. This means that diminishing returns to capital is overcome by technological progress. In other words, marginal product of capital can be permanently sustained (as a constant) above $\rho$, allowing for 
sustained positive per-capita growth. Let us recall that the marginal product of capital is:

$$
\frac{\mathrm{d} Y}{\mathrm{~d} K}=\alpha K_{t}^{\alpha-1}\left(A_{t} L_{t}\right)^{1-\alpha}
$$

For the labour force held constant and $g_{K}=g_{A}$ implies that the marginal productivity of capital held constant. It has to be noted there is still diminishing returns to capital if there was technological progress. What can be gleaned from here is that sustained positive per capita growth in the longrun can be achieved through sustained technological progress. This is important lesson for countries that embark of sustained economic transformation. Economic transformation can be achieved through technological progress.

It has to be mentioned that in the Solow model, the rate of technological progress is exogenous and not explained. That is why it is called exogenous growth model. The preference parameters $\sigma$ and $\rho$ have no impact on the equilibrium growth rate. The same applies to the technological parameter $\alpha$. However, these parameters do influence the steady-state value of investment-output ratio (Equation (24) or (25)). The only parameter that affects the growth rate of the economy is the growth of technology, $g_{A}$, which is exogenous to the model.

\subsection{Implications of the Solow Model ${ }^{1}$}

The derivations in Sections 3.1.1 and 3.1.2 indicate that in the neoclassical growth model sustained or long-run growth in output per worker is achieved through the improvement in technology. Hence more output can be produced with the same inputs through an enhancement in technology. In other words, the neoclassical model predicts that if the level of technology is fixed, capital per worker and output per worker will be constant in the long run and there will be no long-run growth in output per worker. This prediction is largely an implication of diminishing returns. If there are diminishing returns, at some point the costs in terms of foregone consumption of further investment in capital will outweigh the benefits in the form of the additional future output that it will produce so capital per worker will be constant in the long run. Thus, the model predicts that if sustained growth occurs it must be because of technological progress. However, in the neoclassical model, the rate of technological progress, like the rate of population growth, is considered as exogenous and therefore it is assumed to be determined by factors outside the analysis.

An important characteristic of the neoclassical model is its implication that that long-run growth does not depend on saving rate or on longer hours of work by labour. In the model long-run growth depends solely on technological improvements. The saving rate and the quantity of labour only affect the level of output in the neoclassical growth model, and not its growth rate. A lesson that can be drawn here is that technology is central to Africa's economic transformation.

${ }^{1}$ The intuitive explanation given to the Solow model here is heavily influenced by [7]. 
Solow used the neoclassical growth model as a framework for understanding the growth experience of the United States over the previous 40 years. He observed that as technology improves, output per worker and capital per worker will grow at the same rate in the long run, but along the adjustment path to the long-run equilibrium the two will grow at different rates.

To help give an intuitive explanation for the implication of the Solow model let us simplify the growth of output into an empirical equation of the form:

$$
\Delta y=\Delta A+b \Delta k
$$

where $\Delta$ denotes the percentage change, $y$ is output per worker, $A$ is the level of productivity or technology, $k$ is the capital-labour ratio and $b$ is the production elasticity of capital (i.e. the change in output caused by a change in capital). Simply stated, the above formula says that the percentage change or growth rate of output per worker depends on the rate of technological progress and the growth rate of capital per worker.

Given data on output and capital per worker and estimates of the production elasticity of capital, the Equation (26) can be used to determine level of technology A in each period. Based on the above formula and based data from the US, Solow estimated that technological progress accounted for 87.5 per cent of the growth in output per worker in the US from 1909 to 1949, and the remaining 12.5 per cent was due to increases in the capital-labour ratio. Later analysis by [8] suggests that a considerable proportion of growth in the United States stems from increased efficiency of production technological progress. Similar results have also been obtained for other industrialized countries. Indeed, measured by its popularity as a framework for long-run analysis, the neoclassical growth model has been very successful. It has been applied to every major country and extended in numerous directions. However, it still suffers from some limitations.

Furthermore, the neoclassical model is incapable of explaining the productivity slowdowns in the industrialized economies in the 1970s, where we witnessed a clear slowdown in the growth rate of output per worker. This slowdown has been the topic of intense study, and most efforts to account for the productivity slowdown use the framework of the neoclassical growth model described by Equation (26). Some macroeconomists expand the model to include energy as an input into production as well as labour and capital, and thus are able to attribute the rise in energy prices in 1970s to explain the drop in productivity growth. However, the effects that can be identified in the data explain only a small proportion of the observed slowdown. Thus, in the context of the neoclassical growth model, the mid-1970s productivity slowdown must be ascribed to a decline in the rate of technological progress. However, since the model does not explain what determines technological progress, this amounts to ascribing the productivity slowdown to bad luck or to the end of a long period of good luck not a very satisfying explanation.

As pointed out by [9], a deficiency of the neoclassical model has also been its inability to explain why some countries grow faster than others for sustained periods of time. The neoclassical model typically ascribes a large proportion of 
observed growth in anyone country exogenously to technological progress, but since the pace of technological progress is determined outside the analysis, international differences in growth are largely explained by factors beyond the model. [6] therefore argues that the observed international growth experience conflicts with the predictions of neoclassical theory. Neoclassical theory predicts that if technology and capital are easily transportable across international borders, standards of living around the world should converge. The reasoning is as follows. In poor countries, real wages are low so the returns to capital should be high, provided technology can be readily imported. This suggests that capital should flow from rich countries to poor countries, since being rich implies that real wages are high and thus the returns to capital are low. As this adjustment process takes place, real wages in the poor countries should rise, eventually approaching the real wages in the rich countries. The problem is that this story is not a very good characterization of the actual international experience. In fact, the very poorest countries in the world also tend to have the lowest growth rates, so the gap between the rich and the very poorest countries has tended to widen, not to narrow as the theory predicts.

There is a believe among most macroeconomists that business cycles impose large costs on individuals, and therefore society are better off if business cycles could be eliminated or at least made less severe. But, if the goal of economics is to improve the welfare of individuals, then neoclassical growth theory holds little promise. Using a highly stylized model, similarly to Equation (26), to summarize the U.S. economy, [9] suggests that the potential benefits to society of smoother growth are considerably smaller than those of higher average growth in consumption per worker. He concludes that the gains to be made from better macroeconomic stabilization policies, though important are relatively small when compared with the potential benefits of economic policies that could increase growth. While Lucas' results are debatable, most would agree that there are large potential benefits of policies that could increase the sustainable growth rate.

\section{Endogenous Growth Models}

A significant contribution of the neoclassical growth model was to focus attention on the importance of technological progress in growth theory. However, this contribution also highlighted the limitations of the model as a framework for explaining growth. Long-run growth in output per worker is determined by the pace of improvements in technology. But technological progress in the model is not clearly articulated and is seen to occur exogenously at no cost.

Some researchers have attempted to explain the role of technology in a production function such as Equation (1). [10] considers technology as a public input in the production function that is supplied by the government and therefore receives no compensation. [11] and [12] assumes that technology are unintended by products of production or investment or learning-by-doing. Furthermore, discoveries through learning-by-doing automatically spill over to the whole economy. [13] however points out that the models have limitations including the 
failure to capture efforts to develop new products and technologies. Developments of consumer electronic products, computers and pharmaceuticals demonstrates the importance of research and development ( $\&$ \& $)$ efforts in the manufacturing of new products.

Given that economic transformation is an interrelated processes of structural change that accompany economic development, an economy that run on the neoclassical growth model would be able to structurally transform the economy through sustained or long-run growth in output per worker. This can be achieved through technological progress. Hence more output can be produced with the same inputs through an enhancement in technology. Here again emphasis is placed on the importance of technology for Africa's sustainable growth path.

\subsection{Romer's Endogenous Growth Model}

[14] and [15] are credited as the first to formalize the endogenous growth model by the idea that positive spillovers associated with the investment in knowledge could sustain long-run growth in a competitive economy. Romer builds on the ideas of [11], [16], and [17]) to demonstrate that knowledge is an input into the production of goods, as well as a by-product of the production process that benefits all firms. The basic idea is that as a result of investment in physical capital, firms obtain new knowledge, or let us call it learning-by-doing, and this new knowledge improves not only their own productivity, but also that of other firms. This notion is important because a firm's use of existing knowledge in no way diminishes any other firm's ability to use this knowledge. Or, to use the economic term, knowledge is said to be "non-rival." This non-rival property of knowledge is not shared by more tangible inputs such as labour and capital: a worker or a machine can only be in one place at a time.

A key feature of Romer's model is the imperfect competition in the capital goods market. This allows to model firms' activities in $\mathrm{R} \& \mathrm{D}$ be rewarded with monopoly rent for good innovations. By introducing profit-seeking behaviour for a firm's engagement in R \& D activities, Romer is able to explain the role of technological progress in his model.

Romer carefully explains that while each individual firm's investment in knowledge is subject to diminishing returns, diminishing returns can be overcome at the aggregate level because the knowledge generated by each firm benefits all firms. By explaining away diminishing returns, Romer is able to explain how increases in output per worker can be sustained in the long run without assuming that technology fortuitously improves each period.

In the Romer model we also assume that the representative consumer maximizes the present discounted value of its utility as given by Equation (2):

$$
\max \int_{0}^{\infty} U\left(C_{t}\right) \mathrm{e}^{\rho t} \mathrm{~d} t, U\left(C_{t}\right)=\frac{C_{t}^{1-\alpha}}{1-\sigma}, \sigma>0
$$

subject to the following portfolio of assets accumulation rule: 


$$
\dot{A}_{t}=r A_{t}+w_{t}-C_{t}
$$

where the variable $A$ stands for assets and $w$ the wage rate. It is assumed that household supply one unit of labour per unit time. The current value of the Hamiltonian maximised by the representative consumer is therefore of the form:

$$
H_{t}=\frac{C_{t}^{1-\alpha}}{1-\sigma}+\theta_{t}\left[r A_{t}+w_{t}-C_{t}\right]
$$

Using the first order conditions (Equation (6)) and co-state conditions (Equation (7)) we have:

$$
\frac{\mathrm{d} H}{\mathrm{~d} C}=C^{-\sigma}-\theta=0
$$

or

$$
C^{-\sigma}=\theta
$$

Taking the log-differentiation of Equation (30) implies:

$$
g_{c}=-\frac{1}{\sigma} g_{\theta}
$$

From Equation (7) we have

$$
\frac{\mathrm{d} H}{\mathrm{~d} A}=r \theta=\rho \theta-\dot{\theta}
$$

or

$$
\rho-r=\frac{\dot{\theta}}{\theta}=g_{\theta}
$$

Inserting Equation (32) into Equation (31) we obtain the Euler's equation as:

$$
g_{c}=-\frac{1}{\sigma} g_{\theta}=\frac{1}{\sigma}(r-\rho)
$$

Equation (33) gives the balanced growth path solution for the interest rate. Equation (33) is very similar to Equation (13), where the marginal product of capital is equal to the interest rate. Furthermore, it suggests that for the rate of growth of consumption to be positive the interest rate must be greater than the rate of time preference. Intuitively, this implies that one will consume only if when the return on assets are greater than the rate of time preference.

The economy is assumed to undertake production in three sectors: final good sector, the capital goods sector and the $\mathrm{R} \& \mathrm{D}$ sector. The final good $\mathrm{Y}$ is assumed to be produced with labour, $L_{Y}$, and a number $A$ of differentiated durable capital goods, $i$, each produced in quantity $x(i)$. Following Grossman and Helpman it assumed that all capital goods have separable effects on output and therefore the production function of the form:

$$
Y_{t}=L_{Y_{t}}^{1-\alpha} \int_{0}^{A_{t}} X_{t}(i)^{\alpha} \mathrm{d} i
$$

For $A$ constant, the production function exhibits constant returns to scale in $L_{Y}$ and $x(i)$ and diminishing returns in $x(i)$ for fixed $L_{Y}$. As $A$ is productive in the model as well, technological growth is therefore continuous and increases in 
A and therefore prevents diminishing returns to increases in $x(i)$. This is the necessary ingredient for the endogenous growth model.

In the model capital accumulation is given by:

$$
\dot{K}=Y_{t}-C_{t}
$$

Assuming that it takes one unit of foregone consumption to produce one unit of any type of capital good, then $K$ is manufactured according to the following rule:

$$
K_{t}=\int_{0}^{A_{t}} x_{t}(i) \mathrm{d} i
$$

The process of accumulation of technology or designs or innovations is governed by:

$$
\dot{A}_{t}=\delta L_{A_{t}} A_{t}
$$

where $L_{A}$ is the total labour employed in the research sector and therefore

$$
L_{A_{t}}+L_{Y_{t}}=L_{t}
$$

Equation (38) implies that total labour, $L_{t}$, is employed either in the production of final goods or in the research sectors. This implies that all researchers have access to total stock of knowledge A (total number technological designs). It has to be noted that in the endogenous growth model knowledge contributes to the production function in two ways. Firstly, a new technological design corresponds to a new capital good which is used to produce final goods. Secondly, a new technological design increases the total stock of knowledge and therefore increases the productivity of labour in the research sector. Another important assumption is that the proprietor of technological designs has property rights over the production of the capital good but not over the use of the created design in the research sector. That knowledge acts like a public good in the research sector.

Next we assume a perfect competitive environment and that the representative final good producer rents each capital good according to the profit maximization rule:

$$
\frac{\mathrm{d} Y_{t}}{\mathrm{~d} x_{t}(i)}=R_{t}(i)
$$

where $R(i)$, is the rental price of each capital good. Based on Equation (34) and assuming $A$ is independent of $x(i)$ then Equation (40) becomes:

$$
R_{t}(i)=\alpha L_{Y_{t}}^{1-\alpha} X_{t}(i)^{\alpha-1}
$$

For every given value of interest rate, $r$, and $L_{y}$, each capital good producer, having incurred a fixed investment cost in a technological design, $C_{A}$, and the patent for the design, will maximize its net revenue in each period:

$$
\max \pi(i)=R_{t}(i) x_{t}(i)-r_{t} x_{t}(i)
$$

Substituting Equation (16):

$$
\frac{\mathrm{d} \pi(i)}{\mathrm{d} x(i)}=\alpha^{2} L_{\mathrm{Y}_{t}}^{1-\alpha} x_{t}(i)^{\alpha-1}-r=0
$$


Solution to Equation (43) yields:

$$
R(i)=\frac{r}{\alpha}
$$

Equation (44) implies that with constant marginal cost and a constant elasticity of demand $(1-\alpha)$ the capital good producer is monopolist who charges a markup over the marginal cost for his/her product. In other words the firm incurs a fixed cost when it produces a new capital good which it recovers by selling its good for a price $R(i)$ that is higher than the marginal cost.

The decision by the firm to produce a new capital is based on the comparison between the discounted stream of future net revenue that the patent on the good will yield and the cost, $P_{A}$, incurred in obtaining the technological design.

It is assumed that the market for the technological designs is competitive, so that in each period the price of the technological design is equal to the present value of the stream of net revenue the monopolistic capital good producer can extract. In a sense the capital goods producer makes zero profit. The dynamic zero-profit/free-entry condition is then:

$$
P_{A_{t}}=\int_{t}^{+\infty} \mathrm{e}^{-r(\tau-t)} \pi_{\tau}(i) \mathrm{d} \tau
$$

Using Leibniz integral rule or formula to differentiate a definite integral ${ }^{2}$ :

$$
\dot{P}_{A_{t}}=r P_{A_{t}}-\pi_{t}(i)
$$

or

$$
r P_{A_{t}}=\pi_{t}(i)+\dot{P}_{A_{t}}
$$

The implication of Equation (47) is that firms can choose to put the monetary value of $P_{A_{t}}$ into the bank and earn interest, $r P_{A_{t}}$. On the other hand firms could buy a technological design and therefore own a patent for a fee of $P_{A_{t}}$ and earn a return of producing a differentiated good, $\pi_{t}(i)$, plus a capital gain/loss of owning the patent $\dot{P}_{A_{t}}$.

To obtain the balance growth paths of the underlying variables let us recall the Euler Equation (Equation (33)) and Equation (44) which suggest the interest rate, $r$, is constant and therefore $R(i)$ is also constant. Given that all producers have the technological characteristics and face the same market conditions and therefore will have the same equilibrium. This implies that $R(i)=\bar{R}=R$ and $x(i)=\bar{x}=x$. We can therefore express Equation (41) as:

$$
R_{t}=\alpha L_{Y_{t}}^{1-\alpha} x_{t}^{\alpha-1}
$$

and using Equation (44) we have:

$$
x_{t}=L_{Y_{t}}\left[\frac{\alpha^{2}}{r}\right]^{\frac{1}{1-\alpha}}
$$

Given that labour, $L_{Y}$, used in the production of the final good is constant

${ }^{2}$ The Leibniz rule is: $\frac{\partial}{\partial z} \int_{a(z)}^{b(z)} \frac{\partial f}{\partial z} \mathrm{~d} x+f(b(z), z) \frac{\partial b}{\partial z}-f(a(z), z) \frac{\partial a}{\partial z}$. 
the $x$ in Equation (49) is also constant. Now given that all capital good producers produce in the same quantity, total physical capital (Equation (36)) is equal to:

$$
K_{t}=\int_{0}^{A_{t}} x_{t}(i) \mathrm{d} i=A_{t} x_{t}
$$

Based on Equation (50) the production function (Equation (34)) can be expressed as:

$$
Y_{t}=L_{Y_{t}}^{1-\alpha} A_{t} x_{t}^{\alpha}
$$

With $L_{Y}$ and $x$ constant. Now substitute Equation (50) into Equation (51) we have:

$$
Y=K^{\alpha}\left(L_{Y} A\right)^{1-\alpha}
$$

The marginal productivity of capital is

$$
\frac{\mathrm{d} Y}{\mathrm{~d} K}=\alpha K^{\alpha}\left(L_{Y} A\right)^{1-\alpha}
$$

For $L_{Y}$ constant and with physical capital $K$ growing at the same rate as technology A, the marginal productivity of capital is held constant. This implies that the model delivers sustained per-capita growth the same way as the Solow's model. Hence technological progress circumvents diminishing returns to capital. This represents the key feature of the Romer's model. However, unlike the Solow model where technology, $A$, is exogenous, in the model of Romer growth of technology is determined within the model. Let us examine further how growth of technology is endogenous by recalling Equation (37):

$$
\dot{A}_{t}=\delta L_{A_{t}} A_{t}
$$

or

$$
g_{A}=\frac{\dot{A}}{A}=\delta L_{A_{t}}
$$

Equation (54) implies that the growth rate of technology or technological progress depends on the workforce in the research sector, $L_{A}$. This implies that the existence of a balanced growth equilibrium requires that prices and wages are such that $L_{A}$ and $L_{Y}$ remain constant as $A, K, Y$ and $C$ grow at a constant exponential rate.

The labour market satisfies an equilibrium condition such that that wage rate for labour in the final goods market is marginal product of labour. From Equation (51):

$$
w_{Y_{t}}=\frac{\mathrm{d} Y_{t}}{\mathrm{~d} L_{Y_{t}}}=(1-\alpha) L_{Y_{t}}^{-\alpha} A_{t} x_{t}^{\alpha}
$$

and from Equation (54):

$$
w_{A_{t}}=\frac{\mathrm{d} \dot{A}_{t}}{\mathrm{~d} L_{A_{t}}} P_{A_{t}}=\delta A_{t} P_{A_{t}}
$$

Hence imposing the equilibrium condition of equal wages $\left(w_{Y_{t}}=w_{A_{t}}\right)$ in the labour market implies that: 


$$
P_{\mathrm{A}_{t}}=\frac{1-\alpha}{\delta} L_{\mathrm{Y}_{t}}^{-\alpha} x_{t}^{\alpha}
$$

Given that $L_{Y}$ and $x$ are constant then $P_{A}$ is also constant. Taking the logdifferentiation of Equation (57) implies that $\dot{P}_{A}=0$. This implies that Equations (46) or (47) gives the solution of interest rate as:

$$
r=\frac{\pi}{P_{A}}
$$

But using the mark-up of $R(i)=\frac{r}{\alpha}$ and the expression for $R(i)$ in Equation (41) we can express the profit function of Equation (42) as:

$$
\pi=(1-\alpha) \alpha L_{Y_{t}}^{1-\alpha} x_{t}^{\alpha}
$$

Equation (59) and Equation (57) implies that:

$$
r=\frac{(1-\alpha) \alpha L_{Y_{t}}^{1-\alpha} x_{t}^{\alpha}}{\frac{1-\alpha}{\delta} L_{Y_{t}}^{-\alpha} x_{t}^{\alpha}}=\delta \alpha L_{Y}
$$

or

$$
L_{Y}=\frac{r}{\delta \alpha}
$$

Recall that from Equation (54) the growth of technology can be expressed as:

$$
g_{A}=\delta L_{A}
$$

Let

$$
\bar{L}=L_{A}+L_{Y}
$$

Now substitute $L_{A}$ from Equation (63) into Equation (62):

$$
g_{A}=\delta\left(\bar{L}-L_{Y}\right)
$$

or from Equation (61):

$$
g_{A}=\delta \bar{L}-\frac{r}{\alpha}
$$

Equation (65) tells us that output and physical capital grow at the same rate as technology. Furthermore, capital accumulation suggests that consumption also grows at the same rate as $Y$ and $K$. To demonstrate this recall that:

$$
\dot{K}=Y-C
$$

or

$$
\frac{\dot{K}}{K}=\frac{Y}{K}-\frac{C}{K}
$$

A constant growth of capital implies that:

$\dot{g}_{A}=0$ and therefore $\frac{\dot{Y}}{K}=\frac{\dot{C}}{K}$, which if $g_{Y}=g_{K}$, implies that: $\frac{\dot{C}}{C}=\frac{\dot{K}}{K}$.

Hence with a constant population, the per capita growth rates are:

$$
g_{c}=g_{Y}=g_{K}=g_{A}=g
$$


Hence from Equation (65) and substituting for the interest rate from the Euler equation of Equation (33) the equilibrium growth rate and interest rates are:

$$
\begin{gathered}
g=\frac{\alpha \delta \bar{L}-\rho}{\alpha+\sigma} \\
r=\frac{\alpha(\sigma \delta \bar{L}+\rho)}{\alpha+\sigma}
\end{gathered}
$$

Equation (65), which represent the pairs $(r, g)$ of the balanced growth on the production side demonstrate that a negative relationship between the interest rate and growth. This means that a rise in the interest rate lowers the discounted value of the stream of future net revenues from the production of technological designs. This results in labour moving out of the research sector into the final goods sector and therefore reduce the growth technological progress.

On the other the Euler Equation (Equation (33)) represents pairs $(r, g)$ from the balance growth on the consumer's side of the economy. It suggests a positive relationship between the interest rate and growth. This is because a rise in the interest rates raises the return on assets held by the consumer and therefore the growth rate of consumption.

For given values of the parameters, Equations (68) and (69) gives the equilibrium values for the steady growth rate of the economy and the interest rate. It also demonstrates that unlike the neoclassical model, in Romer's endogenous growth model the equilibrium preference parameters $\sigma$ and $\rho$ affect the equilibrium growth rate. The equilibrium growth rate also depends positively on the technology parameter $\alpha$, the capital's share in total income. Furthermore, economic growth is proportional to the size of the labour force. [18], [19] and [20] support [15] by pointing out that a rise in the size of labour causes a rise in technological progress and therefore higher growth rate and a higher interest rate. The relationship between the size of the population and growth is known as scale-effects property.

The scale effects are explained by Equation (37) which suggests that technological growth is proportional to the level of labour working in the research sector. And with constant share of labour in the research sector, then economic growth is proportional to the size of the economy's population. Hence for Africa to achieve credible economic transformation massive investments are needed in $\mathrm{R} \& \mathrm{D}$, particularly in skilled researchers. Furthermore, Africa need a focus on training more in the fields of science, technology, engineering and mathematics (STEM).

It has to be noted that and as explained by [18], [19] and [21], the endogenous growth model allows R \& D to play an important role in sustained growth by allowing for Schumpeter's idea of "creative destruction." This means that in the technology sector old and obsolete designs are quickly replaced by new designs. Also endogenous cycles are caused by new innovations. Furthermore, economic growth is sustained at a positive level in the long-run because of investments in $\mathrm{R} \& \mathrm{D}$ and accumulation of knowledge. 


\subsection{Further Intuitive Explanation of the Romer's Endogenous Growth Model}

Growth accounting exercises in the endogenous growth models can therefore ascribe growth to technological progress, but they do not explain where it comes from or why. In particular, there is only a very limited role for government policy to influence growth in the neoclassical model. While governments may be able to speed the transition to the long-run equilibrium and thereby raise or lower growth temporarily by influencing the allocation of total income between consumption and saving, the model provides no framework for understanding how the activities of governments may influence the long-run growth rate.

Endogenous growth models attempt to address the inadequacies of the neoclassical models. The defining characteristic of the endogenous growth theory is that it tries to account for all the factors responsible for growth rather than attributing large portions exogenously to improvements in technology as is the case in neoclassical models. It has to be noted that the name "endogenous growth theory" stems from the fact that growth in output per worker is determined within the model. The basic question addressed is: How does the selfinterested behaviour of consumers and firms together with the invisible hand of the market produce sustained increases in output per worker?

The endogenous growth model extends the neoclassical growth model by adding to it a theory of how technological progress comes about in a competitive economy. Hence the endogenous growth model is capable of explaining growth than the neoclassical growth. The endogenous growth model is therefore better at addressing the fundamental policy question regarding growth: What can governments, including those in Africa, do to foster economic growth as a means of improving the welfare of their constituents? Within this overall goal of explaining rather than simply accounting for growth, the model can be helpful to African policymakers as the embark on the journey of economic transformation of African economies.

What are the determinants of the endogenous growth model? As illustrated above, a key feature of the neoclassical growth model is that technological enhancement is responsible for increases in output per worker at a diminishing rate. Hence capital is subjected to diminishing returns. The question is then how does an economy overcome diminishing returns. The answer offered by the endogenous growth theory is that there is another input in production in addition labour and capital which can be broadly defined as "knowledge." Knowledge can never be subjected to diminishing returns because one person's use of knowledge does not diminish the ability of others to use it. Knowledge is generally acquired through investment in research and development ( $R \& D)$, invention, innovation and education. These are important lessons for African policymakers.

It has to be noted that the role of knowledge in economic growth is not a new idea. In the 1940s, for example, Joseph Schumpeter pursued this theme and since then a large literature has developed on the microeconomics of R \& D and 
growth, including the link between science and innovation, the importance of patent rights, the protection of intellectual property rights, the diffusion of innovations across firms, industries and countries, and the role of government policies towards R \& D. In the 1960s, Schultz and Becker also carried out a number studies on the investment in knowledge and its contribution to growth. Endogenous growth theory can therefore be seen as extending the neoclassical model to include a microeconomic theory of the accumulation of knowledge in an aggregate or macroeconomic model of long-run growth. Hence technological progress is endogenized in the model. It is important to note that in the endogenous model, "learning-by-doing" and " $\mathrm{R} \& \mathrm{D}$ " are very important for economic growth.

Romer's model provides a potential explanation for why many of the world's poorest countries also have the lowest economic growth rates. Knowledge in Romer's model cannot be simply transferred from rich countries to poor countries. Rather, knowledge must be learned, and learning takes place through the experience of investing in physical capital. In poor countries, including to in Africa, capital is relatively scarce so firms have had little opportunity to acquire knowledge. And this shortage of knowledge itself reduces the productivity of labour and capital, which in turn discourages investment. As a result, poor countries can become trapped in a low-growth equilibrium resulting in an everwidening gap between rich and poor nations. That is why it is crucial that for the success of its transformation agenda, Africa needs to invest heavily in the creation of knowledge.

The strength of the endogenous growth model is that it provides a solid description of how knowledge is generated in a competitive economy through the process of R \& D. It suggests that advances in knowledge provide the engine of long-run growth. The model incorporates knowledge in new technologies which are produced in a separate sector of the economy, the research and development or R \& D sector of the economy. New technologies, like knowledge in general, are non-rival. But in order for there to be an incentive for firms to innovate in a competitive economy, firms must be able partly to control access to the new technologies they develop so as to extract normal rents from the creation of knowledge. Firms can gain some control over access to their innovations by patenting them, thus precluding their use by other firms for a limited period of time. Patents therefore allow firms to profit from the benefits of their innovations, but some of the benefits of new technology still spill over to other firms. This is because patents prevent other firms from using the new technology in production, but the knowledge embodied in the new technology can be used by others to develop still better ideas and products.

What the endogenous growth model tell us is that "learning-by-doing" and $\mathrm{R}$ \& D play important roles in pushing the production possibility frontiers of economies. Examples can be seen in countries where investments in infrastructure, knowledge, and with the development of the financial sector spurs growth and international trade. Knowledge from quality improvements and new goods 
also make substantial improvements in the growth process as well as in the distribution of income. Overall, the implications of the endogenous models in explaining growth and development is very diverse. The important point here is that African policymakers must work hard in creating the necessary enabling environment that will support "learning-by-doing" and R \& D with a view of pushing substantially the growth prospects of African economies.

\section{Unmasking the 7 Percent Growth Rate Prescription: A Digression}

Some development economists constantly advise African countries that for their economies to attain their developments goals they have to grow at an average rate of 7 percent annually. For how long the economies should grow by is often very silent. These economists indicate that maintaining such growth rate is a panacea for all the economic-ills a country faces.

One is always intrigued by where economists find their numbers. Where did 7 per cent growth rate prescription come from? Answers to this question have varied, with some alluding to the number being derived from a general equilibrium model to the number being picked from thin air. This paper argues that the number comes from a simple mathematical construct and not from any complicated computable general equilibrium model. To derive the number let:

$m$ = the scale multiply for the economy

$n=$ the number of years

$\bar{y}=$ the current size of the economy

$g_{i}=$ is the growth rate of the economy in period $i$

then expanding the size of the economy by a factor $m$ implies:

$$
m \bar{y}=\left(1+g_{1}\right)\left(1+g_{2}\right)\left(1+g_{3}\right) \cdots\left(1+g_{1}\right) \bar{y}
$$

or

$$
m \bar{y}=\prod_{i=1}^{n}\left(1+g_{i}\right) \bar{y}
$$

Assuming each period is a year and that the economy grows in each year at an average rate of $\bar{g}$, then Equation (71) becomes:

$$
m \bar{y}=\bar{y}(1+\bar{g})^{n}
$$

therefore

$$
\bar{g}=\sqrt[n]{m}-1
$$

Equation (73) suggests that mangers of a country's economy can compute the growth they desire the economy to grow at after deciding the factor by which they would like the economy to expand by after a number of years. Based on Equation (73), Table 1 presents various growth rates at various values of $m$ and $n$.

The above calculations provide interesting insights. It tells us that if an economy grows at an average of 7 percent each year for a decade it would double its size. If the population grow at rate less than the economy, then living standards 
Table 1. Desired growth rates (g) of an economy in per cent.

\begin{tabular}{ccccccc}
\hline $\mathrm{m} / \mathrm{n}$ & 1.5 & 2 & 2.5 & 3 & 3.5 & 4 \\
\hline 1 & 50 & 100 & 150 & 200 & 250 & 300 \\
2 & 22.47 & 41.42 & 58.11 & 73.21 & 87.08 & 100 \\
3 & 14.47 & 25.99 & 35.72 & 44.22 & 44.22 & 58.74 \\
4 & 10.67 & 18.92 & 25.74 & 31.61 & 36.78 & 41.42 \\
5 & 8.45 & 14.87 & 20.11 & 24.57 & 28.47 & 31.95 \\
6 & 6.99 & 12.25 & 16.50 & 20.09 & 20.09 & 25.99 \\
7 & 5.96 & 10.41 & 13.99 & 16.99 & 19.60 & 21.90 \\
8 & 5.20 & 9.05 & 12.14 & 14.72 & 16.95 & 18.92 \\
9 & 4.61 & 8.01 & 10.72 & 12.98 & 14.93 & 16.65 \\
10 & 4.14 & 7.18 & 9.60 & 11.61 & 13.35 & 14.87 \\
11 & 3.75 & 6.50 & 8.69 & 10.50 & 12.06 & 13.43 \\
12 & 3.44 & 5.95 & 7.93 & 9.59 & 11.00 & 12.25 \\
13 & 3.17 & 5.48 & 7.30 & 8.82 & 10.12 & 11.25 \\
14 & 2.94 & 5.08 & 6.76 & 8.16 & 9.36 & 10.41 \\
15 & 2.74 & 4.73 & 6.30 & 7.60 & 8.71 & 9.68 \\
\hline
\end{tabular}

of that economy will rise significantly. Currently, we observe that Africa economy is growing at a robust rate of 5 percent. If this growth rate should persist each year then it will take Africa about 14 years to double the size of the economy. The call to African governments to engineer 7 percent average annually is perhaps to get the size of the economy to double in a decade.

The interesting point here is that until the financial crisis China' economy was growing at an average rate of 10 percent for a little over two decades. This implies that China expanded its economy over 7 fold in the last 20 years. No wonder it was able to uplift 400 million of its people from poverty in a decade. What this suggests to us is that Africa can bring prosperity to its people if it directs its resources towards getting its economies to grow close to 10 percent for the next decade. This will allow it address most of it development challenges. This can be done through investments in technology, science and technology and infrastructure as well as research and development, factors China paid attention to spurs its remarkable growth. That is why the policy implication of endogenous growth models offers hope for Africa.

\section{Some Policy Implications of the Endogenous Growth Theory for Africa}

In Section 5 we provided simple "back-of-the-envelope" calculations to show how policymakers could decide how they would like the economies to grow so as to achieve levels of expansion of their economies. The endogenous growth model provides a formal framework that can explain how increases in output per worker can be sustained in the long run. It offers an opportunity to understand 
why some economies grow faster than others and what governments can do to foster long-run growth. The richness of the model allows us to draw insightful some policy implications.

The first important lesson we draw from the endogenous growth models is that the invisible hand of competitive markets does not always yield the most efficient allocation of resources. This is because spillovers play an important role in the growth process. Take for an example, self-interested firms' investments in knowledge or R \& D tend to be less what is required for society as a whole since they do not consider the fact that their investment will benefit others. This implies that government should provide investments in knowledge and R \& D by identifying and targeting the relevant sectors so that the benefits of such programmes outweigh the distortionary effects of the taxes required to finance them. Such investments by governments would raise economic growth and welfare. This of course is not a new idea. African governments must follow the practice of some developed economies and subsidize STEM education and R \& $\mathrm{D}$ investment. Nonetheless, the new growth theory provides a framework for understanding and quantifying the effects of such policies.

Second implication of the endogenous growth model is that reducing the barriers to trade can increase the growth rates of economies. It is well understood that trade liberalization allows countries to produce for a larger market and thereby take greater advantage of economies of scale, including the economies or savings in the per unit cost of output associated with increasing the scale of production. This reduces production costs among the trading countries and therefore raises their standards of living. In neoclassical trade theory, the economies of scale associated with greater trade liberalization are predicted to raise the level of economic prosperity among the trading countries. The endogenous growth model strengthens this argument for trade liberalization by pointing out that there are important economies of scale in investment in $\mathrm{R} \& \mathrm{D}$ and opening a channel through which trade may influence long-run growth. Trade also promotes technology transfers and spillovers. The larger is the potential market for a product, the greater will be the incentive to innovate, and with more innovation, knowledge will accumulate more quickly and growth will rise as well as welfare. That is why it is important that the Continental Free Trade Area (CFTA) must be launched with any further delay.

Third, an implication of the endogenous growth theory is that the savings rate and the real interest rate in an economy may influence its long-run growth rate. In the neoclassical growth model, the savings rate and the real interest rate influence the level of output, but not its long-run growth rate. This is because in the neoclassical model, a rise in the savings rate which increases the pool of funds available for investment and lowers the real interest rate will not affect the growth rate of output in the long run. However, the endogenous growth models stress R \& D as the source of growth and therefore the savings rate and the real interest rate typically influence the growth rate of output by affecting the pace of technological innovation. The more consumers are willing to postpone 
consumption, the lower will be the real interest rate, and the less costly it will be to finance investment in $\mathrm{R} \& \mathrm{D}$. Other things being equal, $\mathrm{R} \& \mathrm{D}$ investment and hence the growth rate will therefore be higher. Furthermore, the endogenous growth theory also implies that government policies can have large effects on the welfare of the people on a large scale than the neoclassical growth models because government policies will typically affect both the level and the growth rate of economic activity. King and Rebelo (2000) caution on this policy advice. This because while there is the potential for "good" policies to raise growth and improve welfare, the welfare costs of policies which reduce steady state growth can be large. They examined the predicted effects of a tax increase using both the neoclassical growth model and a simple learning-by-doing endogenous growth model. In the neoclassical growth model, raising the rate of income taxation (when the additional government revenue is used to finance transfers to consumers rather than investment) reduces the ratio of capital to output in the long run resulting in a long-run decrease in the level of output per worker. The growth rate of output per worker is of course unaffected by this tax change. In the learning-by-doing model, in contrast, raising income taxes lowers the growth rate of output per worker in addition to reducing the ratio of capital to output in the long run. As a result, King and Rebelo (2000) find that the negative impact of the tax increase on economic welfare is larger in the learning-by-doing model.

The implication of the endogenous growth model for monetary policy, as with other aspects of government policy, is that the stakes are higher if policy can affect steady-state growth. Over the medium term, monetary policy determines the rate of inflation by controlling the rate of monetary expansion, and through its effect on inflation it influences the economy's potential output and the overall standard of living. Inflation has a negative effect on macroeconomic performance. Inflation also reduces the efficiency of the price system as a means of allocating resources in market economies, it increases uncertainty, and it causes more resources to be expended in managing money balances, in changing prices and in coping with inflation. Inflation also distorts effective tax rates, and alters the value of un-indexed pensions. These various costs of inflation, when viewed in the context of the neoclassical growth model, result in a lower level of output per worker and thus lower levels of income and consumption in the long run. The long-run growth rate of income and consumption are unaffected in the neoclassical model.

\section{Policy Advice and Concluding Remarks}

As each African country may choose to embark on independent policies, the imperative for a continental approach to addressing challenges is stronger now than ever. Hence Africa should continue its efforts to deepen the integration of the continent. As pointed out in [22] [23] [24] some of the continental policies needed to address the economic challenges, transform and build resilient economies may include:

- Agricultural Modernization: African countries need to pursue policies on 
reforming the agriculture sector. A reform of the sector is needed if countries are to embark on an export-oriented growth process. However, any reform of the agriculture sector must start with reforming land tenure system in many countries. African government needs to also invest more in rural infrastructure better seedlings, irrigation systems and technologies. Economic theory suggests that the surpluses generated by small farms in the rural areas of Africa as a consequence of the modernization of the agriculture sector could propel sustainable economic development. This is because the excesses in rural-Africa would lead to the transfer of capital and labour to the towns and cities. The lessons from China and other parts of the world indicates that agriculture is central to any structural economic transformation because its contribution to shared growth and the reduction of poverty and inequality.

- Science and Technology. Africa's development also hinges on the use of science and technology. The work on endogenous growth indicates that science and technology are very important for the advancement in industrialization. This is because advancements in science, technology and innovations lead to enhancing productivity and eventually growth. Experiences from China indicate that the adoption of modern technology started with farmers, which was central to agricultural transformation. The policy targeted smallholder farmers who were the vanguards in the adoption of new technologies and as a result agricultural productivity rose very sharply. Drawing lessons from China, African countries should promote investments in rural infrastructure, including irrigation, and the provision of agricultural research and extension to a majority of farmers. Equally important, African countries should also invest more in research and development in the agricultural sector which will support modernized practices in the agriculture sector.

- Infrastructure: To support any transformation agenda, African countries need to invest more in affordable and efficient infrastructure. Advancement in a country's economy depends largely on electricity, ICTs, roads, rail, airports, seaports, and waterways. The current infrastructure in Africa is poor and cannot support any transformation agenda of the continent as 40 percent of production is lost because of the poor state of infrastructure in Africa. The poor state of infrastructure also increases the cost of doing business in Africa. Hence for Africa to transform its economies investments in infrastructure are needed.

- Strengthening Manufacturing: The manufacturing sector of African economies needs to be strengthened. Currently, Africa's share of global manufacturing value added is declining while those for the Asian countries are rising. Moreover, African economic growth is mainly fuelled by exports of oil, minerals and agricultural commodities. That is why it is extremely important that Africa embark on new approaches to its development agenda through the strengthening of the manufacturing sector. Any approaches should include adding value to agricultural products and employment so as to enhance the value chain in agribusiness and value chain in agriculture, industry and services. 
- Strengthening the management of macroeconomic stability: For they to achieve sustainable development African countries need to strengthen fiscal, debt and cash management systems; reduce domestic debt to more manageable levels and enhance domestic resource mobilization; seek external funding to liquidate part of the domestic debt; ensure consistency in policy implementation and restrain from management through ad hoc policy directives. Such measure is needed to achieve a successful transformation processes.

To conclude, it has to be noted that endogenous growth models is key for understanding long-run growth of economies through the accumulation of knowledge. Private and public investments in knowledge and R \& D have long-run effects on growth. Since small changes in the growth rate of an economy can cumulate into large changes in the standard of living over a generation or more, government policies can have a large impact on economic welfare. Furthermore, endogenous growth models provide a richer structure that can add insight into the mechanics of growth.

The implications of the growth models examined in this paper are that for an African country to achieve economic transformation through an interrelated processes of structural change that accompany economic development, growth has to be at sustainable high levels for a very long time. Furthermore, it is important African policymakers work hard to circumvent diminishing marginal productive of key factors of production. It is also important that adequate resources are invested by African government in research and development, allowing for technological progress, innovations and accumulation of knowledge. A combination of these factors is the necessary ingredient for sustainable high levels of growth. The endogenous growth models hold a lot of promise for the structural economic transformation of African economies.

\section{Acknowledgements}

The author would like to thank profusely Mahamudu Bawumia, Erastus Mwencha, Abdalla Hamdok, Thomas Kwesi Quartey, Eugene Owusu, David Mehdi Hamam, Robert Okello, David Luke, Yao Graham, Fareed Arthur, Talla Kebe, Mzwanele Mfunwa and Benjamin Banda, Omar Bagersh and many more for their valuable discussions and comments on drafts of the paper. The writing of the paper was deeply inspired by participants of the Macroeconomic Policy Dialogues for senior African policymakers I have facilitated around Africa over time. The paper was finalized in Banjul, The Gambia and for that the author thanks Mrs. Peggy Janneh for her generosity, warmth and kindness in ensuring I was comfortable in The Gambia. However, the views expressed in the paper are those of the author and should not be attributed to United Nations Economic Commission for Africa (UNECA). The author is currently Principal Policy Adviser, Capacity Development Division, United Nations Economic Commission for Africa, P. O. Box 3001, Addis Ababa, Ethiopia; email: atta-mensahj@un.org. The author holds a PhD in financial economics from the Simon Fraser University, Vancouver, British Columbia, Canada. 


\section{References}

[1] Syrquin, M. (1988) Patterns of Structural Change. In: Chenery, H. and Srinivasan, T.N., Eds., Handbook of Development Economics, Elsevier, New York, 203-273.

[2] Chenery, H.B. and Taylor, L. (1968) Development Patterns among Countries and over Time. Review of Economics and Statistics, 50, 391-416. https://doi.org/10.2307/1926806

[3] Kuznets, S. (1973) Modern Economic Growth: Findings and Reflections. Nobel Memorial Lecture. American Economic Review, 63, 247-258.

[4] Kuznets, S. (1955) Economic Growth and Income Inequality. American Economic Review, 45, 1-28.

[5] Solow, R.M. (1956) A Contribution to the Theory of Economic Growth. Quarterly Journal of Economics, 70, 65-94. https://doi.org/10.2307/1884513

[6] Lucas, R.E.J. (1990) Why Doesn't Capital Grow from Rich to Poor Countries? American Economic Review, 80, 92-96.

[7] Macklem, T. (1994) Recent Advances in Growth Theory: Perspective and Policy Implications. In: Endogenous Growth Theory, Bank of Canada Review, 37-55.

[8] Denison, E. (1962) The Sources of Economic Growth in the United States. Committee for Economic Development, Washington DC.

[9] Lucas, R.E.J. (1988) On the Mechanics of Economic Development. Journal of Monetary Economics, 22, 3-42. https://doi.org/10.1016/0304-3932(88)90168-7

[10] Shell, K. (1967) Towards a Theory of Inventive Activity and Capital Accumulation. American Economic Review Papers and Proceedings, 56, 62-68.

[11] Arrow, K.J. (1962) The Economic Implications of Learning by Doing. Review of Economic Studies, 29, 155-173. https://doi.org/10.2307/2295952

[12] Sheshinski, E. (1967) Optimal Accumulation with Learning by Doing. In: Karl, S., Ed., Essays on the Theory of Optimal Economic Growth, MIT Press, Cambridge, 31-52.

[13] Helpman, E. (1992) Endogenous Macroeconomic Growth Theory. European Economic Review, 36, 237-267. https://doi.org/10.1016/0014-2921(92)90083-9

[14] Romer, P. (1987) Growth Based on Increasing Returns Due to Specialization. American Economic Review Papers and Proceedings, 77, 56-62.

[15] Romer, P. (1990) Endogenous Technological Change. Journal of Political Economy, 98, 71-102. https://doi.org/10.1086/261725

[16] Ethier, W. (1982) National and International Returns to Scale in the Modern Theory of International Trade. American Economic Review, 72, 389-405.

[17] Dixit, A. and Stiglitz, J. (1977) Monopolistic Competition and Optimum Product Diversity. American Economic Review, 67, 297-308.

[18] Grossman, G. and Helpman, E. (1991) Innovation and Growth in the Global Economy. MIT Press, Cambridge.

[19] Aghion, P. and Howitt, P. (1992) A Model of Growth through Creative Destruction. Econometrica, 60, 323-351. https://doi.org/10.2307/2951599

[20] King, R. and Rebelo, S. (2000) Resuscitating Real Business Cycles. RCER Working Papers, 1, 927-1007. https://doi.org/10.3386/w7534

[21] Rivera-Batiz, L. and Romer, P. (1991) Economic Integration and Endogenous Growth. Quarterly Journal of Economics, 106, 531-555.

https://doi.org/10.2307/2937946 
[22] Atta-Mensah, J. (2015) Toward the Economic Transformation of Africa. ChinaUSA Business Review, 14, 171-184. https://doi.org/10.17265/1537-1514/2015.04.001

[23] Rodrik, D. (2016) An African Growth Miracle? Journal of African Economies, 1-18.

[24] Rioja, F. and Valev, N. (2014) Stock Markets, Banks and the Sources of Economic Growth in Low and High Income Countries. Journal of Economics and Finance, 38, 302-320. https://doi.org/10.1007/s12197-011-9218-3

\section{Scientific Research Publishing}

Submit or recommend next manuscript to SCIRP and we will provide best service for you:

Accepting pre-submission inquiries through Email, Facebook, LinkedIn, Twitter, etc. A wide selection of journals (inclusive of 9 subjects, more than 200 journals) Providing 24-hour high-quality service User-friendly online submission system Fair and swift peer-review system Efficient typesetting and proofreading procedure Display of the result of downloads and visits, as well as the number of cited articles Maximum dissemination of your research work

Submit your manuscript at: http://papersubmission.scirp.org/ Or contact tel@scirp.org 